\title{
PROCESSO DE APLICABILIDADE DO IDENTIFICADOR DE OBJETO DIGITAL (DOI) NA COLEÇÃO DOS PERIÓDICOS DO PORTAL DE PERIÓDICOS ÉLETRÔNICOS DA UNICAMP: UM RELATO DE EXPERIÊNCIA
}

\author{
Santos, Gildenir Carolino ${ }^{1}$ \\ ${ }^{1}$ Universidade Estadual de Campinas/Sistema de Bibliotecas/ppec@unicamp.b
}

\section{RESUMO}

O Digital Object Identifier (DOI) é um identificador que possibilita serviços de caráter complementar e que os metadados deste permite referenciar planos de identificação que utilizam deste identificador. A resolução de um nome DOI pode incluir a resolução para os valores associados, tais como a localização (URL), um endereço de e-mail, outro nome DOI e metadados descritivos. Com essa preocupação, o Portal de Periódicos Eletrônicos Científicos (PPEC), vinculado ao Sistema de Bibliotecas da UNICAMP (SBU), manifestou, junto à Coordenação Geral da Universidade (CGU), o pedido de afiliação à CrossRef / PILA (Publisher International Linking Association) por meio da Associação Brasileira de Editores Científicos (ABEC), visando a aquisição do DOI para ser atribuído aos periódicos credenciados no PPEC. A ferramenta que permite o processo de atribuição do DOI no Portal é Open Journal System (OJS), que já possui integrado ao sistema, um plug-in que habilita a integração ao DOI pela CrossRef, tanto para o fascículo quanto para os artigos dos periódicos. Existem duas formas de realizar a validação do DOI: gerando um arquivo na linguagem XML e enviando pela CrossRef, ou, selecionando os artigos e os registrando dentro do próprio sistema OJS. Obtivemos de imediato, junto a CGU, a liberação para atribuição de 17.000 DOI's em toda coleção de periódicos credenciados no portal da UNICAMP, do período de 2000 a 2016, o que garantiria não somente a persistência de recuperação dos registros (artigos). Concluímos, assim, que esse trabalho planejado, organizado e de total relevância para a Universidade aumentará cada vez mais o impacto na busca por seus periódicos, evidenciando, dessa forma, o quanto uma publicação qualificada e estruturada é capaz de promover a visibilidade e a aceitação junto à comunidade científica. Os editores desempenham um papel importante no apoio à validação dos metadados dos artigos de suas publicações junto ao Portal, garantindo a qualidade da pesquisa.

Palavras-Chave: Identificador persistente, Identificador de objeto digital, DOI, Sistema de informação, Periódicos eletrônicos

\section{INTRODUÇÃO}

Existem várias formas de recuperação da informação periódica na Internet, mas não de maneira eficiente, como, por exemplo, através de um identificador persistente de objeto.

O Digital Object Identifier (DOI) é um identificador que possibilita serviços de caráter complementar e que os metadados deste permite referenciar planos de identificação que utilizam deste identificador. 
De acordo com Brito et al (2015, p.9):

O DOI é um sistema que engloba diferentes subsistemas para o depósito de metadados e a resolução dos nomes DOI. De forma direta, consiste em um par composto por identificador e metadados, em que os metadados podem ser recuperados a partir do identificador. Trata-se de um identificador persistente, único e publicado que gestores de conteúdo vinculam a objetos físicos ou digitais, - que possibilita ofertar serviços e garantir a propriedade intelectual, principalmente para objetos digitais disponíveis na Internet.

Tendo em vista esta perspectiva, o presente trabalho tem como objetivo apresentar o processo de atribuição e controle do DOI nos periódicos do PPEC, a fim de garantir a sua identificação persistente na Internet para efeito da busca e recuperação dos metadados qualificados.

Vale lembrar que o DOI não deve substituir sistemas de identificação como o International Standard Serial Number (ISSN), para as publicações seriadas. O objetivo dele é oferecer serviços complementares, e os metadados obtidos a partir de determinado DOI podem referenciar os esquemas de identificação existentes. A partir desse identificador podem ser buscadas informações e acionados serviços associados a determinado objeto. Ou seja, partindo do DOI, é possível recuperar os metadados atualizados, como sua localização na Internet, seus autores ou quantidade de publicações que fazem referência à entidade associada ao DOI. (INTERNATIONAL DOI FOUNDATION, 2017).

A resolução de um nome DOI pode incluir a resolução para os valores associados, tais como a localização (URL), um endereço de e-mail, outro nome DOI e metadados descritivos. A referência pode ser de vários tipos, e eles nem sempre são diretamente acessíveis no formato de um arquivo digital ou outra manifestação, ou seja, resolução pode ou não retornar uma instância do objeto. A resolução também pode envolver uma ou mais operações de mapeamento intermediário (INTERNATIONAL ORGANIZATION FOR STANDARDIZATION, 2012).

Com essa preocupação, o Portal de Periódicos Eletrônicos Científicos (PPEC), vinculado ao Sistema de Bibliotecas da UNICAMP (SBU), manifestou, junto à Coordenação Geral da Universidade (CGU), o pedido de afiliação à CrossRef / PILA (Publisher International Linking Association) por meio da Associação Brasileira de Editores Científicos (ABEC), visando a aquisição do Digital Identifier Object (DOI) para ser atribuído aos periódicos credenciados no PPEC. O DOI é um identificador persistente único do registro para fontes vinculadas à Internet. (SANTOS, 2016).

$\mathrm{Na} A B E C$, fomos uma das primeiras instituições brasileiras a firmar convênio com a PILA, realizando dessa forma a aquisição do DOI pelo Brasil, e não diretamente pela 
PILA como a maioria das instituições fizeram. A tendência são todas fazerem o processo inverso e realizar a aquisição do DOI diretamente pela $A B E C$, que é a representante oficial da PILA no Brasil.

Conforme o quadro 1, hoje a coleção de periódicos eletrônicos do PPEC conta com 27 títulos de diversas áreas do conhecimento, aguardando em breve a entrada de mais 2 títulos, todos estratificados e qualificados pelo Qualis/Capes, com aproximadamente17 mil artigos para serem validados os DOI's junto à CrossRef

QUADRO 1 - Coleção dos Periódicos do PPEC

\begin{tabular}{|c|c|c|}
\hline Título & Unidade & Área do Conhecimento \\
\hline Brazilian Journal of Oral Sciences & FOP & Ciências Biomédicas \\
\hline Cadernos de Estudos Linguísticos & IEL & Ciências Humanas \\
\hline Cadernos Pagu & PAGU & Ciências Humanas \\
\hline Conceição / Conception & IA & Artes \\
\hline Conexões: Revista de Educação Física & FEF & Ciências Biomédicas \\
\hline Economia e Sociedade & IE & Ciências Sociais Aplicadas \\
\hline ETD - Educação Temática Digital & FE & Ciências Humanas \\
\hline Filosofia e Educação & FE & Ciências Humanas \\
\hline Labor e Engenho & FEC & Tecnológicas \\
\hline LIAMES: Línguas Indígenas Americanas & IEL & Ciências Humanas \\
\hline Manuscrito: Revista Internacional de Filosofia & CLE & Ciências Humanas \\
\hline Opinião Pública & CESOP & Interdisciplinaridade \\
\hline PARC Pesquisa em Arquitetura e Construção & FEC & Ciências Sociais Aplicadas \\
\hline Pitágoras 500 & IA & Artes \\
\hline Pro-Posições & FE & Ciências Humanas \\
\hline $\begin{array}{l}\text { RDBCl: Revista Digital de Bibliot.e Ciência da } \\
\text { Informação }\end{array}$ & SBU & Ciências Sociais Aplicadas \\
\hline Remate de Males & IEL & Ciências Humanas \\
\hline Resgate: Revista Interdisciplinar de Cultura & CMU & Interdisciplinaridade \\
\hline Revista Arqueologia Pública & NEPAM & Interdisciplinaridade \\
\hline Revista HISTEDBR On-line & FE & Ciências Humanas \\
\hline RUA & LABEURB & Interdisciplinaridade \\
\hline Segurança Alimentar e Nutricional & NEPA & Interdisciplinaridade \\
\hline Serviço Social e Saúde & $\mathrm{HC} / \mathrm{SS}$ & Ciências Humanas \\
\hline Terrae Didatica & IG & Ciências da Terra \\
\hline Trabalhos em Linguística Aplicada & IEL & Ciências Humanas \\
\hline URBANA & $\mathrm{IFCH}$ & Ciências Humanas \\
\hline Zetetiké: Revista de Educação Matemática & FE & Ciências Humanas \\
\hline
\end{tabular}

Fonte: Elaborado pelo autor 


\section{MÉTODO}

Os editores e assistentes da Universidade vinculados ao PPEC verificam, após a publicação do fascículo, se o mesmo está em conformidade com os metadados. Após a verificação, é iniciado o processo de validação desse fascículo e seus artigos na CrossRef.

A ferramenta que permite o processo de atribuição do DOI no Portal é Open Journal System (OJS), que já possui integrado ao sistema, um plug-in que habilita a integração ao DOI pela CrossRef, tanto para o fascículo quanto para os artigos dos periódicos.

Optou-se pelo controle por artigos, pois ele facilita a validação de cada DOI junto à CrossRef, cujo pagamento é efetuado a cada três meses por meio da ABEC.

Existem duas formas de realizar a validação do DOI:

1) gerando um arquivo na linguagem $X M L$ e enviando pela CrossRef, ou;

2) selecionando os artigos e os registrando dentro do próprio sistema OJS.

A diferença é que realizando a validação do arquivo XML, gerado dos artigos selecionados por meio do OJS, conectamos à CrossRef por meio de login e senha que recebemos após a afiliação com a PILA/ABEC, e recebemos a comunicação de validação por e-mail feita pela CrossRef, permitindo assim, um controle mais efetivo dos arquivos encaminhados para validação.

Pela validação do registro via pelo sistema OJS, a verificação da validação só é possível através da conexão à CrossRef, pois não recebemos confirmação por e-mail se aquela validação foi concretizada, e só poderemos saber somente realizando essa conexão.

Assim temos a constituição do número de DOI de cada artigo dos periódicos da UNICAMP formada pela estrutura padrão do OJS (fig.1): 


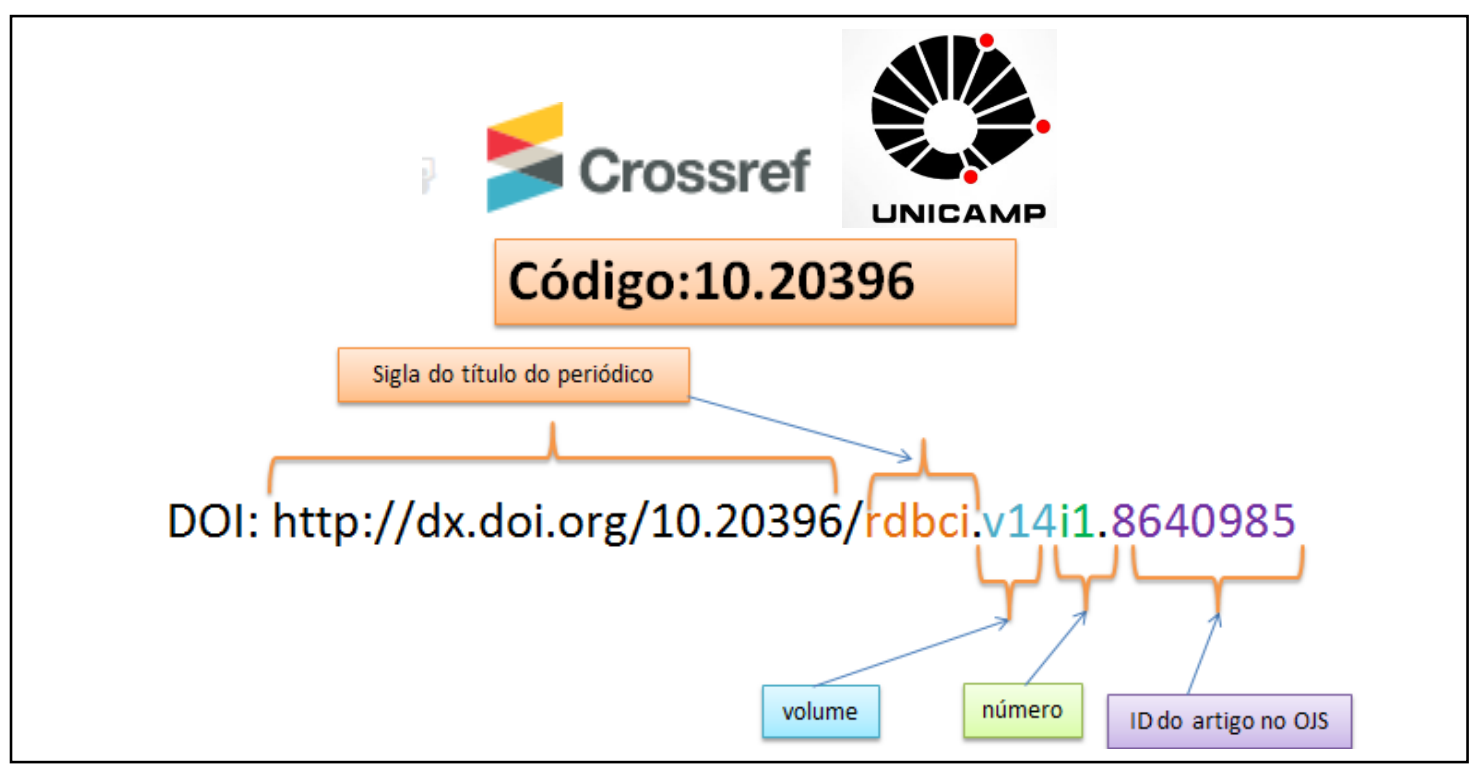

Figura 1: Estrutura da constituição do DOI da UNICAMP Fonte: Elaborada pelo autor / OJS.

Após a realização da validação, por ambas as formas, realiza-se um controle, por meio de uma planilha Excel, fixando as telas de XML gerados enviados à CrossRef e artigos selecionados dos OJS para fins de pagamento à ABEC (fig.2).

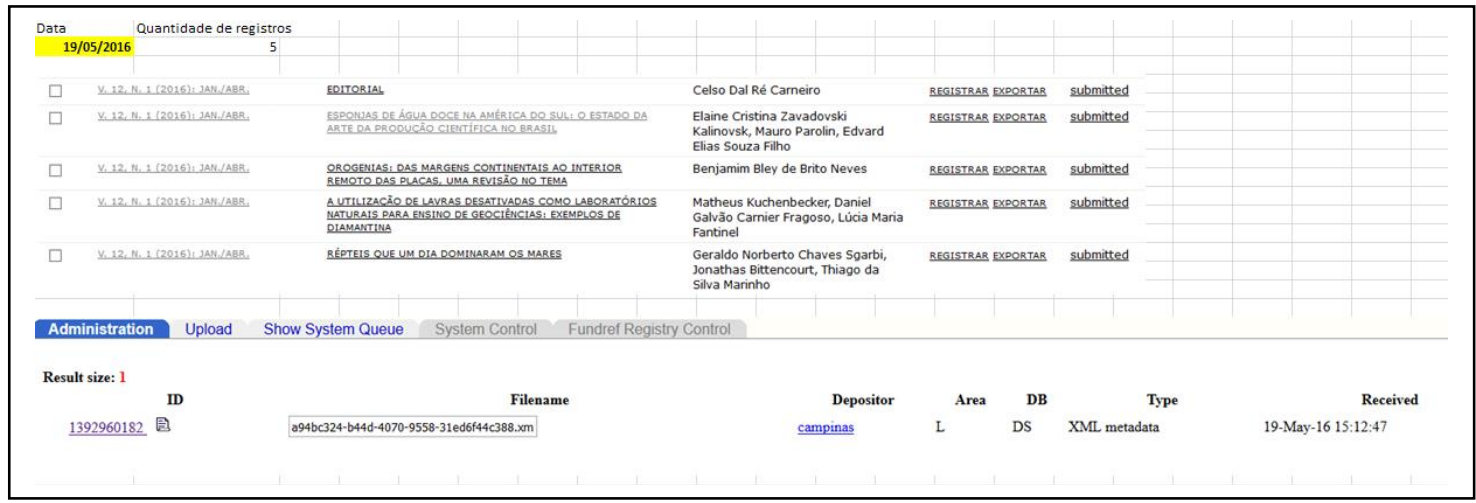

Figura 2: Controle dos artigos OJS e validados na CrossRef Fonte: Elaborada pelo autor

\section{RESULTADOS}

Obtivemos de imediato, junto a CGU, a liberação para atribuição de 17.000 DOls em toda coleção de periódicos credenciados no portal da UNICAMP, do período de 2000 a 2016, o que garantiria não somente a persistente de recuperação dos registros (artigos), mas também a internacionalização dos artigos e periódicos editados pela UNICAMP (SANTOS, 2016). 


\section{CONCLUSÃO}

Concluímos, assim, que esse trabalho planejado, organizado e de total relevância para a Universidade aumentará cada vez mais o impacto na busca por seus periódicos, evidenciando, dessa forma, o quanto uma publicação qualificada e estruturada é capaz de promover a visibilidade e a aceitação junto à comunidade científica.

Os editores desempenham um papel importante no apoio à validação dos metadados dos artigos de suas publicações junto ao Portal, garantindo a qualidade da pesquisa.

\section{REFERÊNCIAS}

BRITO, Ronnie Fagundes de et al. Guia do usuário do Digital Object Identifier. Brasília : Instituto Brasileiro de Informação em Ciência e Tecnologia, 2015. 62 p. ISBN: 978-85-7013-113-3. Disponível em: < http://www.abecbrasil.org.br/ arquivos/Guia usuario DOI-online3.pdf>. Acesso em: 15 abr. 2017.

INTERNATIONAL DOI FOUNDATION. DOI: The DOI system: ISO 26324. Jan . 2017. Disponível em: <https://www.doi.org/>. Acesso em: 15 abr. 2017.

INTERNATIONAL ORGANIZATION FOR STANDARDIZATION. ISO 26324:2012: Information and documentation - Digital object identifier system. 2012. Disponível em: <https://www.iso.org/obp/ui/\#iso:std:iso:26324:ed-1:v1:en>. Acesso em: 15 abr. 2017.

SANTOS, Gildenir Carolino. Sustentabilidade e visibilidade da produção científica: a construção do portal de periódicos eletrônicos científicos da UNICAMP. In: SEMINÁRIO NACIONAL DE BIBLIOTECAS UNIVERSITÁRIAS, 19.; 2016, Manaus. Anais do... Manaus: UFAM, 2016. ISSN: 2359-6058. Disponível em: < http://periodicos.ufam. edu.br/anaissnbu/article/view/3283>. Acesso em: 15 abr. 2017. 